\title{
Preliminary analysis of geological disaster and water circulation system
}

\author{
Yubin Zhang ${ }^{1, *}$ \\ ${ }^{1}$ National Earthquake Response Support Service, Beijing 100049, P. R. China
}

\begin{abstract}
China is a country with frequent geological disasters. First of all, the occurrence of geological disaster will cause great loss of life and property. Secondly, disasters cause changes in topography and landforms, which also have an impact on the natural environment. In a sense, the occurrence of geological disasters and the natural environment are mutually affected. The occurrence of geological disasters is closely related to the soil and water environment. The improvement of regional water circulation system can obviously reduce the occurrence of geological disasters. This paper analyzes the causes of geological disasters. This paper introduces the water environment improvement programs in the United States, Britain and China.
\end{abstract}

\section{Geological disaster and environment}

The national geological disaster report of the National Bureau of statistics in 2018 shows many important contents. In 2018, 2966 geological disasters occurred in China. Including 1631 landslides, 858 collapses, 339 mudslides, 122 ground collapses, 9 ground fissures and 7 land subsidence. They account for 55\%, 28.9\%, 11.4\%, $4.1 \%, 0.3 \%, 0.2 \%$ of the total geological disasters. As a result, 105 people were killed, 7 missing and 73 injured, with a direct loss of 1.47 billion RMB. These figures are $25 \%$ lower than in 2017. As shown in Figure1.

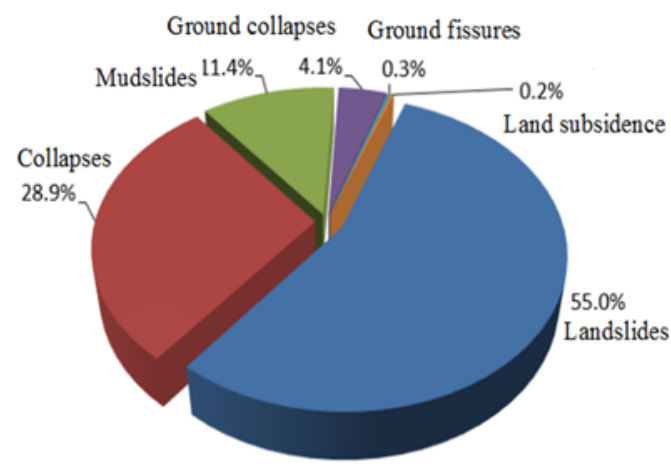

Fig.1. Proportion distribution of disaster types

Among 2966 geological disasters, 2738 were caused by natural factors, accounting for $92.3 \%$ of the total, 228 by human factors, accounting for $7.7 \%$ of the total. Natural factors are mainly earthquakes and rainfall, while human factors are mainly mining, tunnel engineering, urban construction, etc.

In the past 20 years, with the rapid development of China's economy, civil construction has become the source power of economic development. For example, highway construction, railway construction, tunnel engineering, real estate construction, etc. Most of the central and western regions of China are mountainous areas, with relatively backward urban infrastructure. The Chinese government has invested a lot of money in the construction of roads and railways in mountainous areas. Improve the traffic conditions in backward areas, so as to stimulate the local economy.

The mountain engineering has to excavate the mountain and use the limited cutting slope to carry out various engineering construction, which brings about the problem of slope stability.

Geological disasters change the original topography and form a new geological environment. Engineering construction activities also changed the original topography and increased the possibility of disasters. Therefore, the interaction between geological disasters and natural environment in Central China is more frequent. We can't prevent pure natural disasters, but we should minimize artificial losses. How to balance economic benefits and environmental losses is a serious topic. In the past decade, the Chinese government has formulated a number of laws and regulations to protect the natural environment, especially the water and soil conservation of river basins. On the one hand, it can protect water resource, on the other hand, it can prevent geological disasters.

\section{Evaluation and analysis of geological disaster}

\subsection{Evaluation method of geological disasters}

At present, the research on geological hazards is mainly based on their vulnerability and risk. The difference between risk assessment and vulnerability assessment lies in the different objects of assessment. The

*Corresponding Author:617650460@qq.com 
occurrence of geological disasters is determined by internal and external factors. The internal factors include rock type, water system environment, vegetation cover and so on. External factors include weather, earthquake, artificial explosion, etc.

The assessment of susceptibility focuses on the assessment of the possible time, space and scale of geological disasters. The susceptibility evaluation only evaluates the physical process of geological disasters. The assessment of susceptibility is different from the prediction of probability of occurrence of geological disasters. Probability prediction will take earthquake frequency and rainfall as important reference indexes. The risk assessment tends to focus on the impact of geological disasters on human activities and the harm to human life and property [1].

Therefore, the vulnerability assessment is based on the geological environment assessment of natural conditions, while the risk assessment emphasizes the impact of natural conditions on human activities [2]. The transition from vulnerability assessment to risk assessment should not only consider the interaction of environmental factors, but also consider the impact and damage to human activities [3].

\subsection{Environmental characteristics of induced geological disasters}

Environmental characteristics are the internal causes of geological disasters and the premise and foundation of geological disasters. Environmental characteristics include several core elements, such as geological structure, formation lithology, slope, elevation, hydrogeology and river cutting, etc. [4].

\subsubsection{Geological structure}

Faults cause rock mass instability. The rock exposure accelerated the differentiation. Fold structure will increase the amount of water in geological body. Therefore, geological structure is one of the main factors affecting the development of geological disasters.

\subsubsection{Formation lithology}

There is a positive correlation between the stability of formation lithology and the possibility of geological disaster. Stable formation lithology is less likely to cause disasters. Unstable formation lithology is likely to cause disaster.

\subsubsection{Slope}

Under the action of the earth's gravity, slope is a prerequisite for the formation of most geological disasters. It provides power for the occurrence of geological disasters.

\subsubsection{Altitude}

In the same area, elevation and rainfall are coupled, which directly affect the growth of vegetation. Different vegetation types and vegetation coverage ratio of different heights lead to different retention of rainwater.

\subsubsection{Hydrogeology and river cutting}

Hydrogeology is one of the main factors leading to geological disasters. Most geological disasters and environmental problems are related to pore water. River cutting produces valley terrain, which is easy to cause landslides and collapses.

\subsection{Inducing factors of geological disasters}

The induced factors of geological disaster mainly include earthquake, precipitation and engineering construction.

\subsubsection{Earthquake}

$\mathrm{P}$ wave, $\mathrm{S}$ wave and $\mathrm{L}$ wave are generated immediately when the earthquake occurs. Seismic waves exist in the form of mechanical conduction. The vibration produced by the three waveforms will destroy the rock mass structure, generate new faults and cracks, and destroy the stability of the slope. Earthquake may directly or delay to cause collapse, landslide and other disasters.

\subsubsection{Precipitation}

Precipitation will reduce the cohesion of rock and soil, soften the structure of rock and soil, and increase the load of rock and stratum on the slope. Precipitation will increase the formation water content, destroy the original mechanical balance of rock mass, and induce geological disasters.

\subsubsection{Engineering construction}

Engineering construction will also aggravate the occurrence of geological disasters. When a dam is built, the rise of the water surface will erode the mountains and lead to landslides. Excavation of tunnels, mountain roads and reclamation of barren mountains lead to vegetation destruction and directly or indirectly lead to geological disasters [5].

\section{Impact of urban construction on water environment}

Three inducement factors of geological disasters are mentioned above. Earthquakes and precipitation are natural induced factors and are not controlled by human beings. The water system in the natural environment is related to both geological disasters and human activities. Human activities are controllable factors. With the development of urbanization in China, the impervious pavement increases and the area of farmland and forest decreases. I will describe the relationship between water 
environment and geological disasters from two aspects of surface runoff and groundwater.

\subsection{Increase of surface runoff}

It has been proved that there is a linear relationship between total runoff and impervious area. When the impervious surface connected to each other reaches $8 \%$ $12 \%$, the slight change of the surface water permeability ratio may lead to the significant change of the river condition [6]. A large number of impervious materials are used in urban construction to form a large area of closed surface. Such as roads, squares, parking lots and other underlying surfaces do not have runoff infiltration function.

The increase of urban impervious area leads to the decrease of infiltration rate and evaporation rate. As a result, the peak discharge of rainwater and flood runoff increases and the arrival time of flood peak shorten. Forest land, mountains and water bodies are also replaced by impervious ground, and the remaining bare soil is also compacted. The damage of soil structure, the decrease of porosity and the loss of permeability affect the supply of groundwater. As a result, the natural water circulation system was destroyed, resulting in urban waterlogging.

Urban waterlogging is a phenomenon of water accumulation on the urban ground caused by regional heavy rainfall or continuous rainfall exceeding the regional drainage capacity [7]. Because of the low standard of rain and flood management and construction, China has become a country with high incidence of waterlogging disaster. A survey of 400 towns in the South and east of China by the Ministry of construction shows. In 2010-2015, more than $35 \%$ of towns were hit by waterlogging.

On the one hand, it will cause the paralysis of urban transportation, electric power, telecommunication system, and economic losses. On the other hand, the water circulation system is damaged, which increases the risk of geological disasters.

\subsection{Groundwater reduction}

Urban construction will produce a large number of impermeable grassroots, which will have an impact on the infiltration mechanism and cannot supplement groundwater. Urban construction will produce a large number of impermeable grassroots, which will have an impact on the infiltration mechanism and prevent the replenishment of groundwater. At the same time, the decrease of groundwater quantity leads to the decrease of water pressure and the increase of land subsidence risk. Land subsidence is defined as a slow change geological disaster in the regulations on prevention and control of geological hazards in China. When the land subsidence occurs in a large range, a subsidence funnel will be formed [8]. According to Chinese news reports, land subsidence is the most serious in the middle and east of China due to excessive exploitation of groundwater. Land subsidence is common in ten provinces of China, with the subsidence of more than $200 \mathrm{~mm}$ in an area of about 8 square kilometers. In addition, nearly 50 towns have formed subsidence funnels due to the serious land subsidence.

Because land subsidence is a long and slow process, it is difficult to detect and measure. Many local governments have not invested sufficient resources to pay attention to and survey. Land subsidence is a process from quantitative change to qualitative change. It's only a few millimeters a year, and it's going to be amazing in a few years. The hazards of land subsidence include road collapse, destruction of public facilities and even threat to the safety of residents.

I have analyzed the land reclamation of lakes in southern cities of China. Lake filling is an important cause of urban waterlogging and land subsidence. At present, it has been paid attention by the land department of the government. The risk has been reduced [9].

\subsection{Improvement plan}

EPA, Maryland Environment Agency, proposed low impact development (LID) in 1990. The core is to balance the natural water cycle by controlling the types of projects and protecting the soil. The application of ecological technology can reduce the impact of construction projects on water environment. Considering the water environment of the whole area and the specific runoff problem, the circulation technical measures close to the natural system are taken.

In 1999, the sustainable urban drainage system (SUDS) was proposed in the context of sustainable development strategy. On the one hand, it is to improve the traditional urban drainage system and transform it into a sustainable drainage system that can maintain a good water cycle. On the other hand, it is similar to LID in the United States. The concept of natural circulation is used to improve the circulation quality of infiltration, conservation, utilization and evaporation of rainwater in cities. International Union of resilience city defines elastic city as the ability to digest and absorb external interference and disasters, and maintain the original characteristic structure and main functions.

In combination with this capability, China proposed the plan of building sponge city in 2013. The water quality, quantity, landscape and ecological value of rainwater runoff are taken into consideration to improve the overall water cycle of the city. The core concept of sponge city is about the balance of water ecology and water security. Water ecology includes water infiltration, water storage and water purification. Water safety includes vegetation coverage and soil stability. Sponge city is a planning concept returning to natural circulation. The environment itself can resist low-level geological disasters through self circulation. As shown in Figure2. 


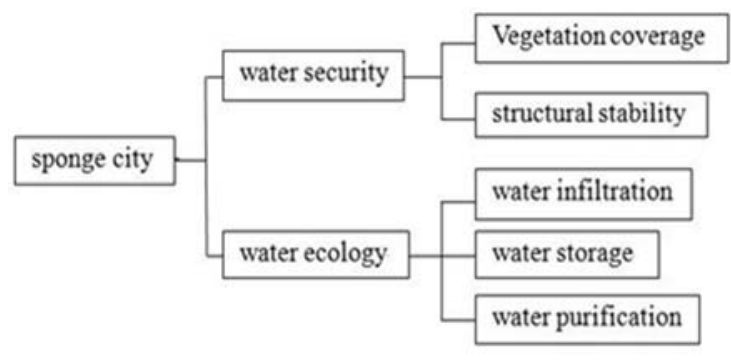

Fig.2. Core concept of sponge City

\section{Conclusion}

This paper introduces the environmental characteristics and induced factors of geological disasters. After the occurrence of geological disasters, the original geological environment will be changed, especially the state of water system. Large scale Lake filling, road paving and tunnel excavation also change the original geological environment. Engineering construction increases the risk of geological disasters. The natural circulation of groundwater and surface runoff is the foundation of stable geological structure.

In order to reduce the impact of engineering construction on the water environment, China has formulated a strict environmental protection system. The natural circulation of regional water system is realized through the sponge city construction plan. On the one hand, it has stabilized the geological structure and vegetation coverage ratio. On the other hand, it increases the ability to resist geological disasters. It will be an important research field in the future to prevent geological disasters by restoring and simulating natural ecological cycle.

\section{References}

1. Favas P J C, Pratas J, Gomes M E P, et al, Selective chemical extraction of heavy metals in tailings and soils contaminated by mining activity, Journal of Geochemical Exploration (2011), 111(3):160-171

2. Z. Wang, L.N. Zhao, et al, Research on the Areal Precipitation Calculation Method for Dammed Lakes in Wenchuan Earthquake Disastrous Areas, Meteorological Monthly (2010), 6:7-12

3. White W B. Water-Formed Structures. Book Reviews: Geomorphology and Hydrology of Karst Terrains (1989), 243:1618-1619

4. Y.H. Liu, H. Deng, Q.Y. Xiong, Evaluation of the vulnerability of slope geological hazards in Maoxian County Based on AHP, Journal of Yangtze River Scientific Research Institute(2017), 34(5):31-35

5. L.X. Dai, Q. Xu, X.M. Fan, A preliminary study on the spatial distribution of geological hazards induced by Jiuzhaigou earthquake in Sichuan Province, Journal of Engineering Geology (2017),25(4):1151-1164

6. L. J. Lyons, P. Kanehl, and R. Bannerman. Impacts of Urbanization on Stream Habitat and Fish Across
Multiple Spatial Scales, Environmental Management (2001), 28(2):255-266

7. W. Che, Z. Yang, Y. Zhao, J.Q. Li, Analysis of urban waterlogging control and drainage system in China, China Water \& Wastewater (2013), 16: 13-19

8. Regulations on prevention and control of geological disasters, China (2004)

9. Y. B. Zhang, Risk analysis of geological disaster based on urban construction, $7^{\text {th }}$ Academic Conference of Geology Resource Management and Sustainable Development, GRMSD2019 (2020):669-674 